\title{
Crescimento e desenvolvimento de milho: acúmulo de massa seca do grão(1)
}

\begin{abstract}
Agostinho Dirceu Didonet ${ }^{(2)}$, Osmar Rodrigues ${ }^{(3)}$, Justino Luiz Mario ${ }^{(4)}$, Francisco Ide ${ }^{(4)}$ e Daniela Tissot ${ }^{(5)}$
Resumo - O objetivo deste trabalho foi estudar o efeito de diferentes épocas de plantio na taxa e na duração do período de enchimento dos grãos, e de que modo esses fatores determinam o peso final dos grãos de híbridos do milho (Zea mays L.). Três experimentos foram instalados no campo, nos anos de 1994-1995 a 1996-1997, com os híbridos comerciais C-901, XL-560 e XL-678, em 1994/95, e os híbridos C-901, XL-212 e XL-370, nos outros anos. Os tratamentos consistiram em diferentes datas de plantio de setembro a dezembro, em 1994/95, e de agosto a dezembro, em 1995/96 e 1996/97. A taxa efetiva do enchimento dos grãos foi diretamente dependente da temperatura média do ar, tendo sido maior nos plantios mais precoces, e resultando em grãos mais pesados do que os obtidos em plantios mais tardios. Nos plantios mais tardios, a menor temperatura do ar durante o período efetivo do enchimento dos grãos propiciou menor taxa de enchimento dos grãos, tornando-os mais leves. Conclui-se que o principal fator limitante do rendimento de grãos nesses plantios é a fonte produtora de fotoassimilados, e não a capacidade dos grãos em acumulá-los.
\end{abstract}

Termos para indexação: Zea mays, enchimento do grão, taxa de crescimento, temperatura, componentes de rendimento.

\section{Growth and development of maize: accumulation of grain dry matter}

\begin{abstract}
The objective of this work was to study the effect of different sowing dates on the rate and duration of the grain filling and how such factors determine the final grain weight of a number of maize (Zea mays L.) hybrids. Three experiments were carried out under field conditions in the years 1994/95 to 1996/97, using the commercial hybrids C-901, XL-560, and XL-678 in 1994/95 and the hybrids C-901, XL-212, and XL-370 in the remaining years. The treatments consisted of sowing dates from September to December, in 1994/95, and from August to December, in 1995/96 and 1996/97. The effective grain filling rate depended directly on the mean air temperature and it was higher in earlier plantings, resulting in heavier grains, as compared to the grains obtained in the later sowings. In the later sowing dates a lower air temperature during the effective grain filling period favors a lower grain filling rate, resulting in lighter grains. In such sowing dates it is concluded that the main factor limiting yield seems to be the source of assimilate supply instead of the grain accumulation capacity.
\end{abstract}

Index terms: Zea mays, seed filling, growth rate, temperature, yield components.

(1) Aceito para publicação em 26 de junho de 2000.

(2) Embrapa-Centro Nacional de Pesquisa de Arroz e Feijão, Caixa Postal 179, CEP 75375-000 Santo Antônio de Goiás, GO. E-mail: didonet@enpaf.embrapa.br

(3) Embrapa-Centro Nacional de Pesquisa de Trigo, Caixa Postal 451, CEP 99001-970 Passo Fundo, RS. E-mail: osmar@cnpt.embrapa.br

(4) Braskalb Agropecuária Brasileira Ltda., Rua Benjamin Constant, 630 ap. 503, Centro, CEP 99010-130 Passo Fundo, RS.E-mail: justino.1.mario@mansanto.com, ide@mansanto.com

${ }^{(5)}$ Rua Santa Cruz, 150 ap. 112, Bairro Alemães, CEP13416-762 Piracicaba, SP. E-mail: dtissot@ carpa.ciagri.usp.br

\section{Introdução}

A temperatura é um dos principais fatores de ambiente que afeta o desenvolvimento da planta de mitho (Zea mays L.), com efeitos importantes nas diversas fases fenológicas da planta. $\mathrm{O}$ aumento na taxa de crescimento e a diminuição na duração do período de enchimento dos grãos são causados pelo aumento da temperatura (Muchow, 1990). Quando os grãos experimentam altas temperaturas durante a fase de acumulação de massa seca, a taxa efetiva de cres- 
cimento de grão é alta, resultando normalmente em grãos mais pesados. Ao contrário, quando a acumulação de massa seca nos grãos ocorre em temperaturas mais amenas, a taxa de crescimento efetiva do grão é menor, resultando em grãos mais leves.

A capacidade dos grãos (dreno) em alocar e utilizar os fotoassimilados produzidos (fonte) e as interrelações entre esses fatores determinam o potencial de rendimento da cultura de milho (Magalhães \& Jones, 1990a, 1990b). Alguns autores confirmam que o rendimento de grãos é limitado, principalmente pela capacidade de suprimento de assimilados pela fonte produtora (Tollenaar \& Daynard, 1978; Schoper et al., 1982), enquanto outros consideram a capacidade dos grãos em armazenar os fotoassimilados disponíveis como causa limitante ao rendimento de grãos (Magalhães \& Jones, 1990a, 1990b). Segundo esses autores, esta limitação dos grãos em acumular biomassa poderia estar relacionada com o esgotamento da capacidade potencial dos grãos em acumular massa seca, sendo, portanto, esse potencial, limitado pelo potencial genético da planta. Considerando que o número de grãos está estreitamente relacionado com o rendimento final do milho (Cirilo \& Andrade, 1994b), condições desfavoráveis de ambiente durante o desenvolvimento dos grãos podem causar abortamento destes (Jacobs \& Pearson, 1991), diminuir o número de grãos e, conseqüentemente, reduzir a capacidade dos drenos de mobilizar fotoassimilados.

Durante o crescimento dos grãos, que genericamente situa-se entre a fertilização e a maturação fisiológica, a fase linear do enchimento dos grãos, que ocorre após uma fase "lag" e imediatamente antes da maturação fisiológica, é quando mais de $90 \%$ da massa seca do grão é acumulada (Johnson \& Tanner, 1972; Tollenaar, 1977). Assim, nessa situação, deve ser considerada a partição de massa seca entre as estruturas vegetativas e reprodutivas, que é afetada pela quantidade da radiação interceptada, pela taxa de crescimento da cultura no florescimento e pelo tempo em que os grãos permanecem acumulando massa seca (Tollenaar, 1977; Aluko \& Fischer, 1988; Grant, 1989; Cirilo \& Andrade, 1994a). Por exemplo, a ocorrência de temperaturas mais amenas após o pendoamento aumenta o período efetivo de crescimento dos grãos e reduz a taxa de crescimento e o peso final dos grãos (Jones et al., 1985; Ouattar et al., 1987), situação típica de plantios efetuados em épocas mais tardias (Cirilo \& Andrade, 1994a, 1994b, 1996). Esses últimos autores concluíram que o menor peso dos grãos resultante de plantios tardios é decorrente de limitação da fonte produtora de fotoassimilados, e que, em plantios mais precoces, o acúmulo de massa seca nos grãos é limitado pela capacidade dos grãos em armazená-los.

Densidades das plantas acima e abaixo de um ótimo têm um efeito negativo na eficiência com a qual a cultura converte radiação interceptada em capacidade de armazenamento do grão (Andrade et al., 1993b). Ensaios de sombreamento artificial durante o crescimento de grãos e condições que limitam a interceptação de radiação e o suprimento de assimilados demonstram não haver efeito na taxa de crescimento dos grãos, mas sim, uma redução no tempo de crescimento, e, conseqüentemente, grãos mais leves (Tollenaar, 1977; Setter \& Flannigan, 1986). Esse efeito do sombreamento artificial simula, na realidade, uma limitação no rendimento de grãos pela fonte produtora de assimilados, típico de plantios efetuados com densidade de plantas acima do ótimo, principalmente em plantios mais tardios.

O objetivo deste trabalho foi avaliar o efeito de diferentes épocas de plantio na taxa e na duração do período de enchimento dos grãos, e de que modo esses fatores determinam o peso final dos grãos de híbridos do milho.

\section{Material e Métodos}

Os ensaios foram conduzidos no campo experimental da Embrapa-Centro Nacional de Pesquisa de Trigo (CNPT), localizado no Município de Coxilha, RS $\left(28^{\circ} 15^{\prime} \mathrm{S}, 52^{\circ} 24^{\prime} \mathrm{W}\right.$ e altitude de $\left.687 \mathrm{~m}\right)$, durante os anos agrícolas de 1994/95, 1995/96 e 1996/97. Sempre que necessário, houve o suprimento de água por meio de irrigações, e as condições de fertilidade não foram limitantes. Usaram-se $250 \mathrm{~kg} /$ ha de adubo da formulação 5-30-12 e $120 \mathrm{~kg}$ de N/ha, tendo sido aplicados $60 \mathrm{~kg} / \mathrm{ha}$ logo após a emergência e $60 \mathrm{~kg} /$ ha quando as plantas apresentavam seis a oito folhas. No ano de 1994/95, foram plantados os híbridos comerciais C-901, XL-560 e XL-678 em quatro épocas de semeadura, com emergência ( $50 \%$ dos coleóptilos visíveis) em 18 de setembro, 13 de outubro, 11 de novembro e 12 de dezembro. Em 1995/96 e 
1996/97, usaram-se os híbridos comerciais C-901, XL-212 e XL-370 em cinco épocas de semeadura, com emergência em 1으 de setembro, 2 de outubro, 27 de outubro, 21 de novembro e 19 de dezembro no ano de 1995/96, e em 1996/97 a emergência ocorreu em 29 de agosto, 29 de setembro, 4 de novembro, 26 de novembro e 22 de dezembro. Em cada ano, o plantio foi efetuado no sistema plantio direto, com densidade de 6,25 plantas $/ \mathrm{m}^{2}$. Os experimentos foram delineados em blocos ao acaso, com três repetições, e as parcelas experimentais foram constituídas de seis linhas de $10 \mathrm{~m}$ de comprimento, com espaçamento de $0,80 \mathrm{~m}$ entre linhas.

Os dados meteorológicos foram obtidos do posto meteorológico da Embrapa-CNPT, localizado a cerca de $10 \mathrm{~km}$ do local do ensaio. $\mathrm{O}$ acúmulo de massa seca nos grãos foi determinado desde o espigamento $(50 \%$ das espigas da área útil da parcela com estigmas visíveis) até a maturação fisiológica (aparecimento da "capa-preta" em $50 \%$ dos grãos da parte mediana das espigas), sendo amostradas, duas vezes por semana, duas espigas de um lote de plantas previamente demarcadas dentro de cada estádio fenológico. Amostras de 50 grãos da parte mediana das espigas foram colocadas em estufa a $60^{\circ} \mathrm{C}$ sob ventilação forçada, até a obtenção de peso constante. A inclinação da equação de regressão entre peso individual dos grãos e dias após o florescimento, durante a fase linear de acúmulo de massa seca, foi usada para estimar a taxa efetiva do crescimento dos grãos de cada tratamento, e o período efetivo de crescimento dos grãos foi determinado pela divisão entre massa final e taxa efetiva do crescimento dos grãos (Johnson \& Tanner, 1972). O acúmulo de biomassa da parte aérea no espigamento e na maturação fisiológica foi determinado em amostras de dez plantas, colhidas respeitando-se uma adequada borda na linha de plantas e, depois secadas em estufa até a obtenção de peso constante. Os números de sementes por espiga e sementes por unidade de área e o peso final da semente foram determinados na amostragem efetuada na maturação fisiológica. O rendimento de grãos, corrigido para $13 \%$ de umidade, foi determinado em uma área útil correspondente a duas linhas centrais de $8 \mathrm{~m}$ de comprimento, totalizando $12,8 \mathrm{~m}^{2}$.

\section{Resultados e Discussão}

O acúmulo de massa seca nos grãos do híbrido de milho superprecoce C-901, durante os anos de 1994/95, 1995/96 e 1996/97, evidencia que os plantios efetuados mais tardiamente tendem a acumular menos massa seca no grão do que os plantios efetuados mais precocemente (Figura 1). A taxa efe-

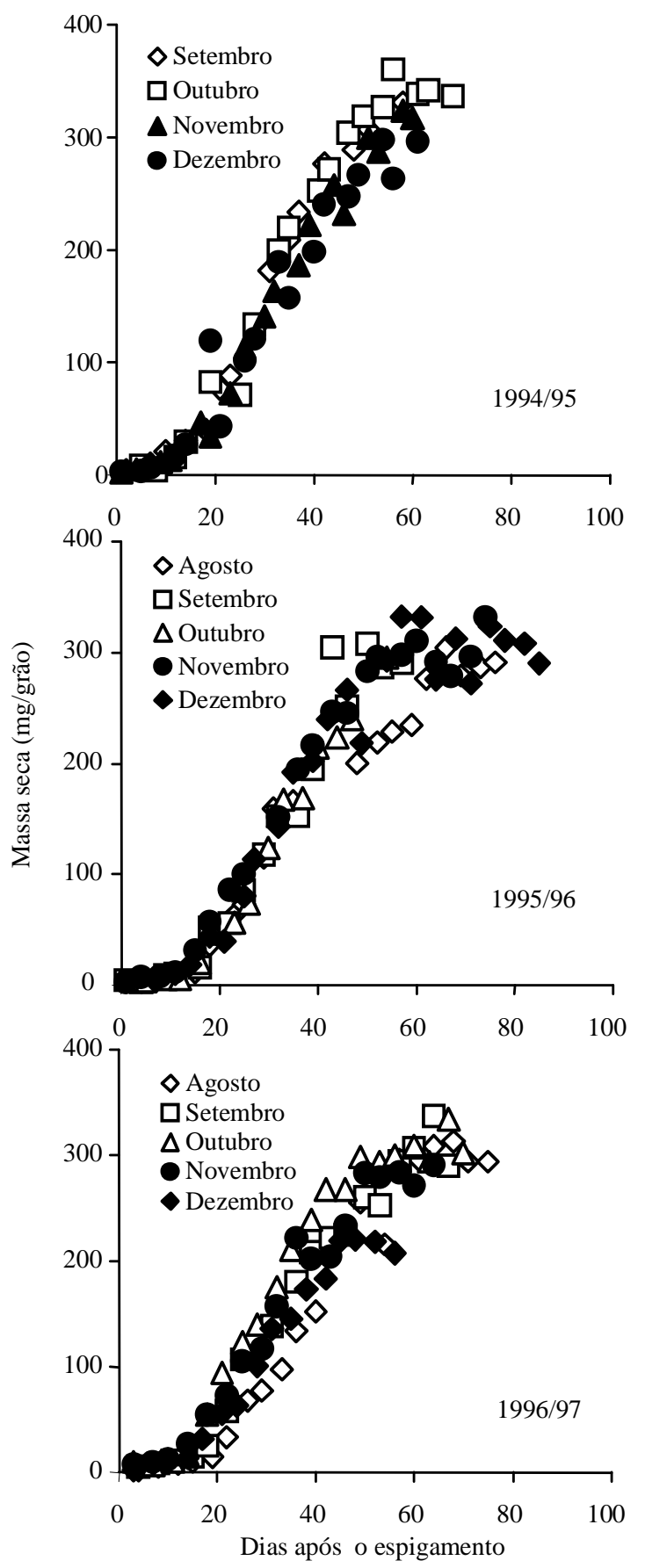

Figura 1. Acúmulo de massa seca de grãos após o espigamento em diferentes épocas de semeadura do milho híbrido C-901, nos anos de 1994/95, 1995/96 e 1996/97. 
tiva de crescimento dos grãos, incluindo os três anos de cultivo, teve relação direta com a temperatura média do ar na faixa de 20 a $24^{\circ} \mathrm{C}$, com um coeficiente de regressão de $0,38 \mathrm{mg} /$ dia por ${ }^{\circ} \mathrm{C}\left(\mathrm{R}^{2}=0,70\right.$, $\mathrm{P}<0,0001$; Figura 2A). Isso sugere que a menor taxa de crescimento dos grãos em plantios mais tardios foi conseqüência da menor temperatura. Da mesma forma, a massa seca final do grão foi menor em plantios mais tardios e teve também uma relação direta com a taxa efetiva de crescimento de grãos $\left(\mathrm{R}^{2}=0,48, \mathrm{P}<0,01\right.$; Figura $\left.2 \mathrm{~B}\right)$, demonstrando, assim, que houve menor acúmulo de massa seca no grão quando a taxa de crescimento desses grãos foi menor. Além disso, o menor período efetivo de crescimento do grão resultou também em menor massa seca acumulada nos grãos $\left(R^{2}=0,37, P<0,05\right.$; Figura $2 C$ ).

Nos híbridos de ciclo precoce, XL-560 cultivado em várias épocas no ano de 1994/95 e XL-212 cultivado nos anos de 1995/96 e 1996/97, a massa final de grãos foi afetada pela época de plantio, sendo menor nos plantios efetuados mais tardiamente (Figura 3). Esses híbridos também apresentaram uma taxa efetiva de crescimento de grãos diretamente dependente da temperatura na fase linear do crescimento dos grãos, com um coeficiente de regressão de $0,42 \mathrm{mg} / \mathrm{dia}$ por ${ }^{\circ} \mathrm{C}\left(\mathrm{R}^{2}=0,68, \mathrm{P}<0,001\right.$; Figura 4A). Por sua vez, o maior acúmulo final de massa seca nos grãos também foi dependente de uma maior taxa $\left(R^{2}=0,39, P<0,05\right.$; Figura $\left.4 B\right)$ e período efetivo de crescimento desses grãos $\left(R^{2}=0,55\right.$, $\mathrm{P}<0,01$; Figura $4 \mathrm{C}$ ).

Os híbridos de ciclo tardio, XL-678 cultivado no ano de 1994/95 e XL-370 cultivado nos anos de 1995/96 e 1996/97, também apresentaram menor massa seca final de grãos nos plantios mais tardios (Figura 5). As taxas efetivas de crescimento dos grãos, tanto do híbrido XL-678 $\left(\mathrm{R}^{2}=0,99, \mathrm{P}<0,01\right.$, coeficiente de regressão de $0,25 \mathrm{mg} /$ dia por ${ }^{\circ} \mathrm{C}$ ) quanto do híbrido XL-370 ( $\mathrm{R}^{2}=0,72, \mathrm{P}<0,01$, coeficiente de regressão de $0,29 \mathrm{mg} / \mathrm{dia}$ por ${ }^{\circ} \mathrm{C}$ ), foram dependentes da temperatura (Figura 6A). A massa seca final acumulada nos grãos em ambos os híbridos também foi dependente da taxa efetiva $\left(R^{2}=0,65\right.$, $\mathrm{P}<0,0005$; Figura 6B) e do período efetivo de crescimento dos grãos $\left(R^{2}=0,69, P<0,0003\right.$; Figura $\left.6 C\right)$.

Esses resultados indicam que a taxa efetiva de crescimento dos grãos, assim como o incremento de massa seca do grão de milho, são fortemente afetadas pela temperatura. Nos híbridos de ciclo mais tardio estudados, a taxa efetiva de crescimento dos grãos
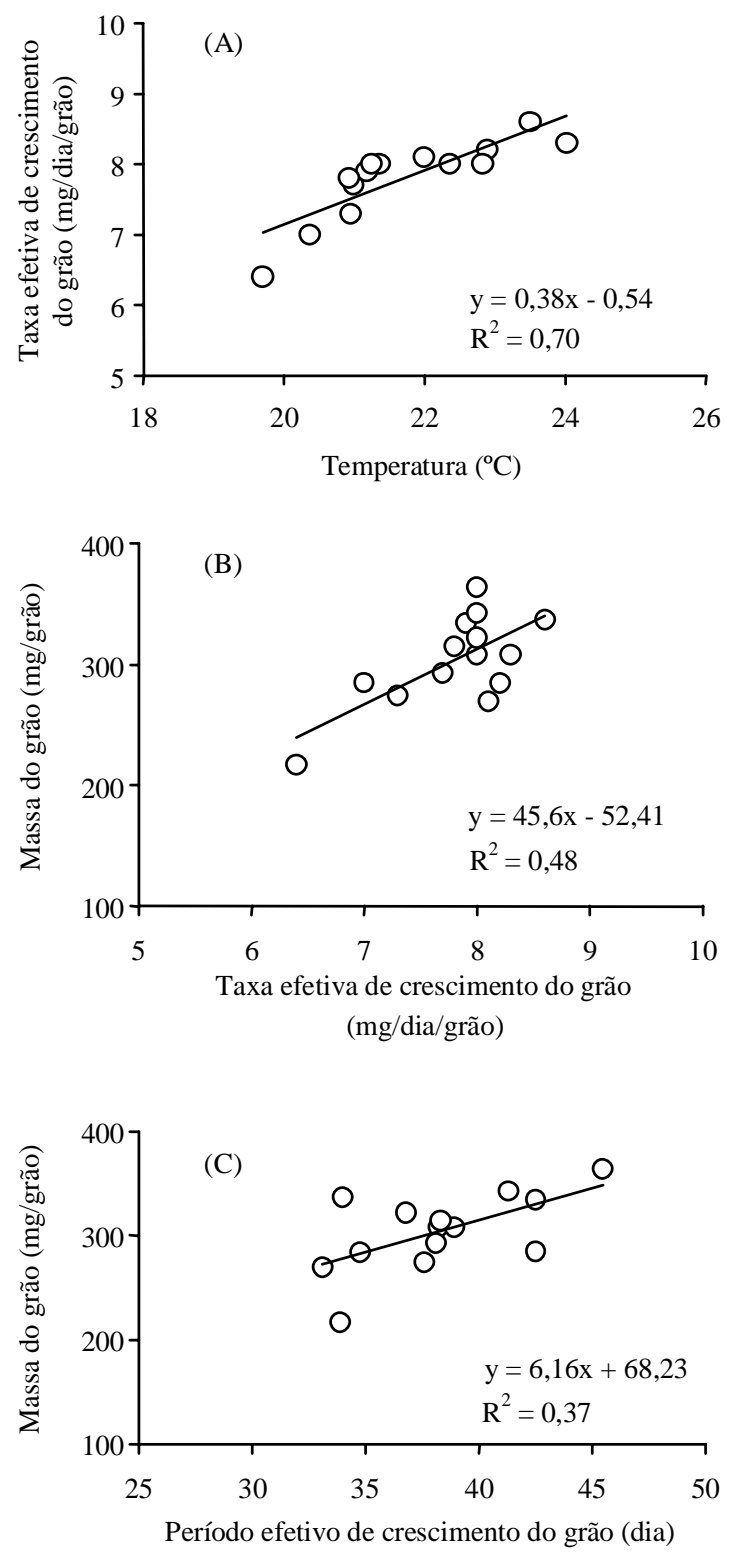

Figura 2. Relação entre taxa efetiva de crescimento de grãos e temperatura média durante a fase de crescimento linear dos grãos (A) e entre massa seca final e taxa efetiva de crescimento de grãos (B) e período efetivo de crescimento de grãos (C) do milho híbrido C-901, durante os anos de 1994/95, 1995/96 e 1996/97. 
foi menor e diferenciada daquelas observadas nos híbridos de ciclo precoce e superprecoce, em virtude de a fase de crescimento dos grãos nesses híbri-

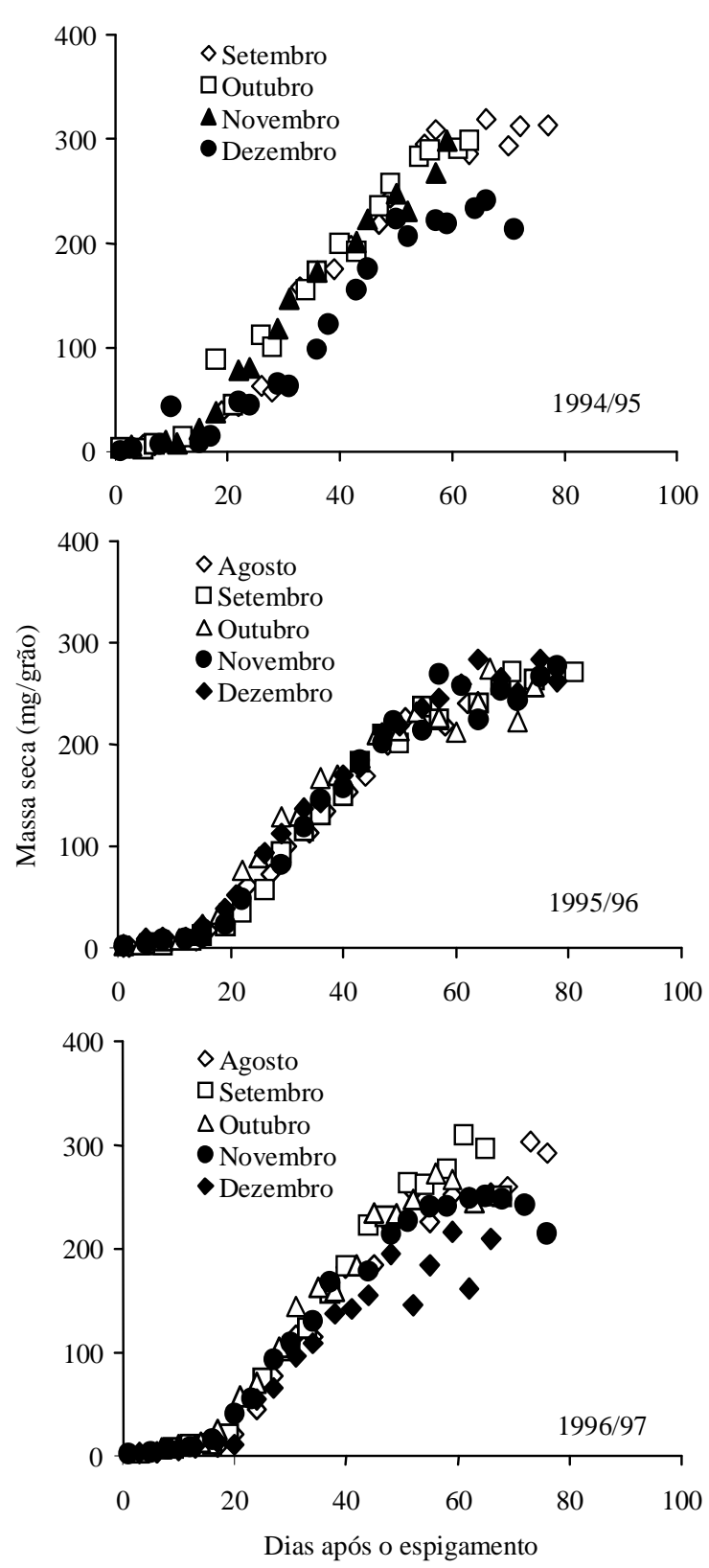

Figura 3. Acúmulo de massa seca de grãos após o espigamento em diferentes épocas de semeadura dos milhos híbridos: XL-560 durante o ano de 1994/95 e XL-212 durante os anos de 1995/96 e 1996/97. dos ter ocorrido posteriormente à dos híbridos de ciclo mais precoce, portanto em temperaturas mais baixas.
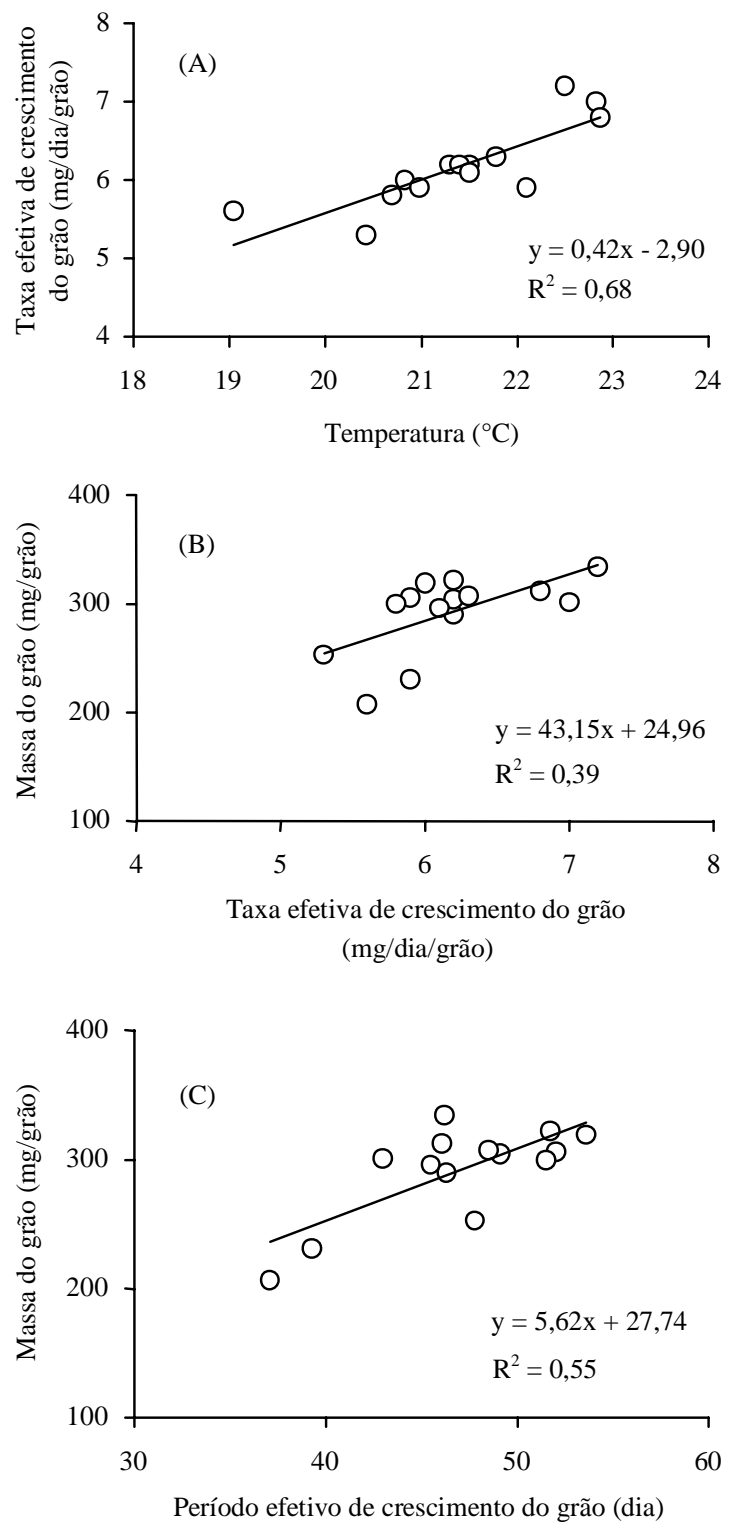

Figura 4. Relação entre taxa efetiva de crescimento de grãos e temperatura média durante a fase de crescimento linear dos grãos (A) e entre massa seca final e taxa efetiva de crescimento de grãos (B) e período efetivo de crescimento de grãos (C) dos milhos híbridos: XL-560 durante o ano de 1994/95 e XL-212 durante os anos de 1995/96 e 1996/97.

Pesq. agropec. bras., Brasília, v. 36, n. 3, p. 447-456, mar. 2001 
No presente estudo, o incremento da massa seca total dos híbridos nos três anos de cultivo após o espigamento foi geralmente superior ao rendimento de grãos (Figura 7), o que indica que não houve li-
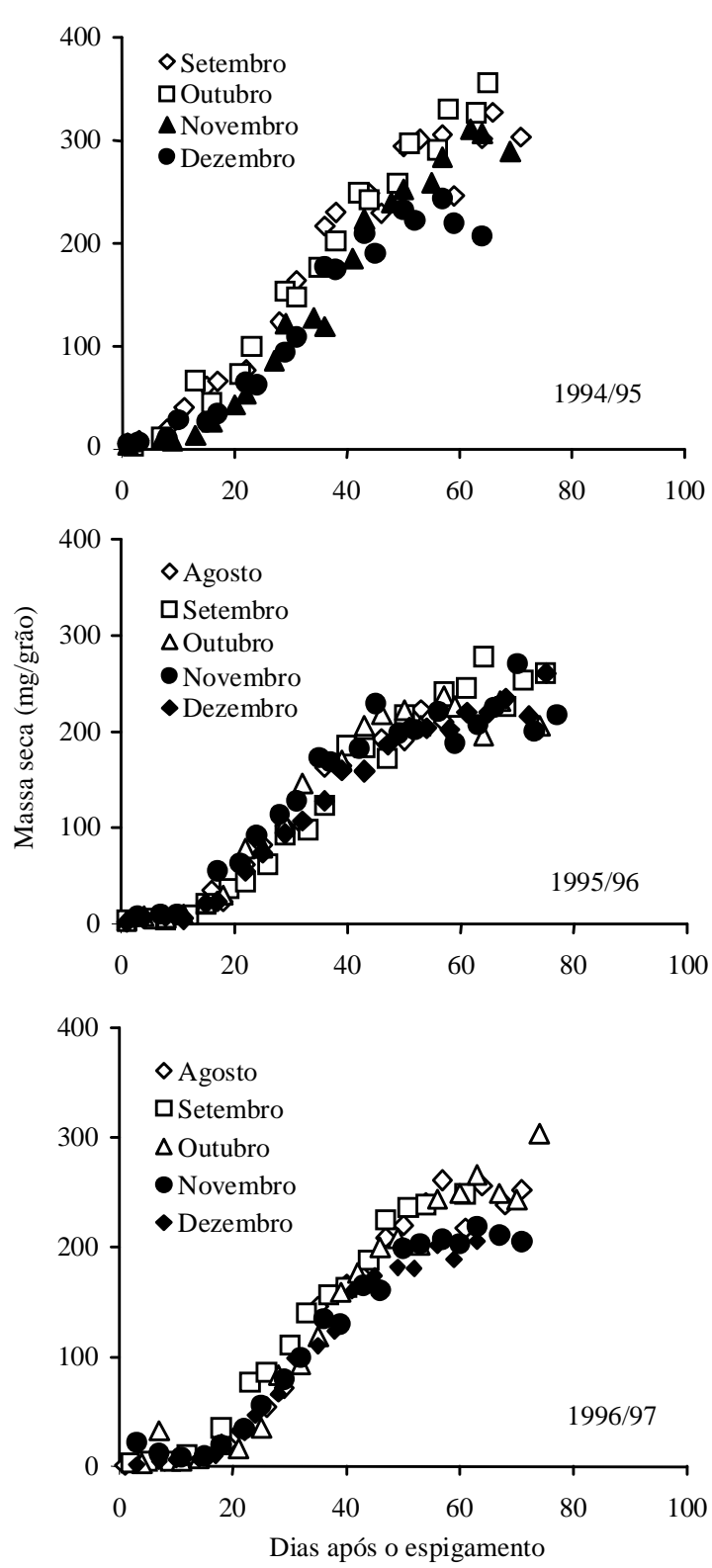

Figura 5. Acúmulo de massa seca de grãos após o espigamento em diferentes épocas de semeadura dos milhos híbridos: XL-678 durante o ano de 1994/95 e XL-370 durante os anos de 1995/96 e 1996/97.
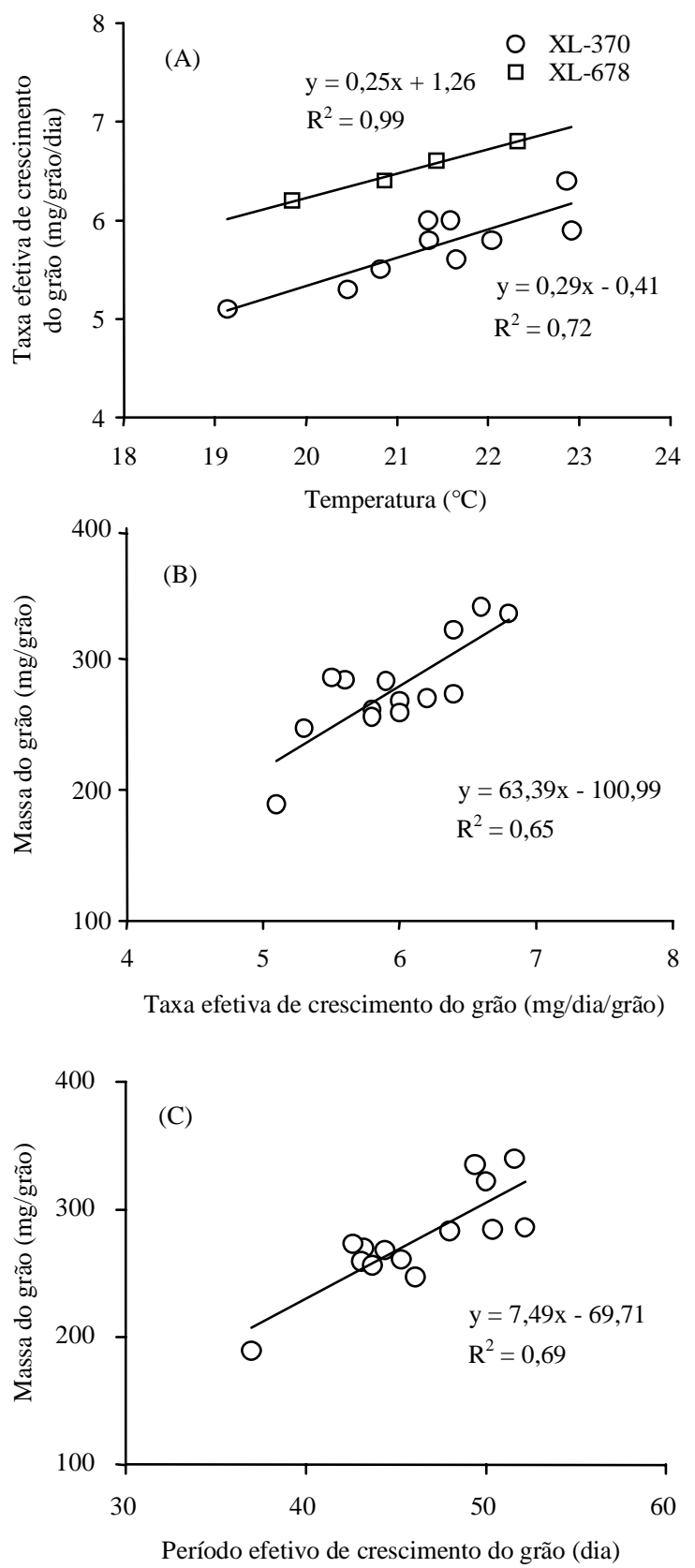

Figura 6. Relação entre taxa efetiva de crescimento de grãos e temperatura média durante a fase de crescimento linear dos grãos (A) e entre massa seca final e taxa efetiva de crescimento de grãos (B) e período efetivo de crescimento de grãos (C) dos milhos híbridos: XL-678 durante o ano de 1994/95 e XL-370 durante os anos de 1995/96 e 1996/97. 
mitação da fonte produtora de assimilados nesse período (Otegui et al., 1995). No entanto, em condições de ambiente com temperatura do ar menor que $19^{\circ} \mathrm{C}$ e com menor radiação solar incidente, os grãos adquirem menor peso final, pela menor taxa fotossintética corrente e menor partição de assimilados para os grãos (Maddonni et al., 1998). Ao contrário, altas temperaturas durante e/ou antes do estabelecimento da capacidade dos drenos, resulta em redução na acumulação de massa seca, e determina, basicamente, menor número de grãos, para promover um ajuste no balanço entre suprimento e demanda de fotoassimilados que ocorrerá durante o período do crescimento dos grãos (Tollenaar et al., 1994). Tal situação pode ter ocorrido no presente estudo, com relação principalmente aos plantios efetuados em épocas mais tardias, em que as altas temperaturas, observadas antes e durante o espigamento, possivelmente provocaram redução na eficiência de transformação da radiação interceptada em biomassa. Em plantios mais precoces, como a temperatura antes do espigamento é menor, houve maior eficiência de transformação da radiação interceptada em massa seca, porém a acumulação total de biomassa foi menor, em virtude da menor taxa de

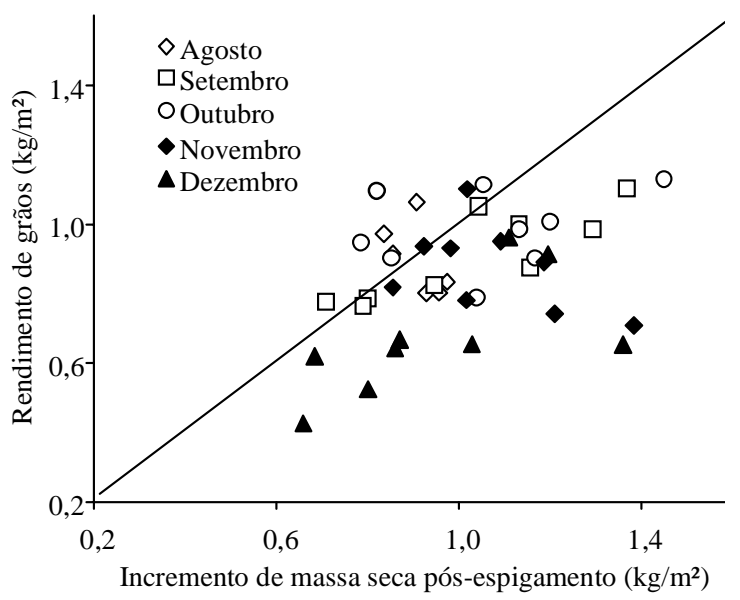

Figura 7. Relação entre rendimento de grãos e incremento de massa seca total da parte aérea no período compreendido entre o espigamento e a maturação fisiológica dos híbridos de milho C-901, XL-560, XL-678, XL-212 e XL-370, durante os anos de 1994/95, 1995/96 e 1996/97. A linha representa a relação $1: 1$. crescimento da cultura, motivos que determinaram menor número de grãos do que a capacidade de suprimento de fotoassimilados possibilitaria durante 0 crescimento dos grãos.

A taxa efetiva de crescimento dos grãos, de $0,3 \mathrm{mg} /$ dia por ${ }^{\circ} \mathrm{C}$, próxima à encontrada neste trabalho, foi observada em experimentos na Argentina, onde foi estudado um único híbrido (Cirilo \& Andrade, 1996). Naqueles trabalhos, plantios tardios efetuados no mês de dezembro reduziram significativamente a taxa efetiva de crescimento de grãos, quando comparados a plantios precoces efetuados nos meses de agosto e setembro, independentemente do ciclo de maturação do híbrido, como conseqüência da diminuição da temperatura média que ocorre nesse período (Giauffret et al., 1991; Tollenaar, 1992). A redução na taxa de crescimento de grãos diminui a massa seca final de grãos, o número de grãos por planta e o número de grãos por unidade de área, em decorrência da menor temperatura e taxa fotossintética (Cirilo \& Andrade, 1994a, 1994b). Tais observações poderiam explicar a diminuição da taxa efetiva do crescimento dos grãos em plantios mais tardios (Figuras 2B, 4B, 7B).

Como a acumulação final de massa no grão depende, basicamente, da disponibilidade de fotoassimilados, pode-se supor que a menor massa seca de grãos observada em plantios mais tardios seja conseqüência de menor disponibilidade de fotoassimilados, caracterizando a fonte como fator limitante (Tollenaar \& Daynard, 1978; Tollenaar, 1989). Assim, quando a fonte se torna limitante em razão da baixa temperatura, nem mesmo o aumento no período efetivo de crescimento do grão seria suficiente para compensar a menor taxa efetiva de crescimento de grãos, resultando, assim, em menor peso final de grãos (Jones et al., 1996). Por outro lado, quando o crescimento dos grãos ocorre em temperaturas altas, entre $25^{\circ} \mathrm{C}$ e $32^{\circ} \mathrm{C}$, o aumento da taxa efetiva de crescimento dos grãos, com correspondente encurtamento do período, só não reduz o rendimento de grãos se a radiação incidente for proporcional ao aumento da temperatura (Muchow, 1990). Esse aumento da taxa efetiva de crescimento de grãos é verificado quando o plantio é efetuado em épocas mais precoces, situação em que o crescimento vegetativo e o acúmulo de biomassa antes do 
espigamento ocorrem em temperaturas mais amenas, as quais aumentam substancialmente, justamente no período crítico de definição do número de grãos. Essa condição reduz o número de grãos, tornando-os mais pesados e caracteriza uma menor limitação da fonte produtora de assimilados, uma vez que a biomassa acumulada em pré-espigamento e a fotossíntese corrente parecem capazes de suportar as altas taxas de crescimento dos grãos. Vários autores têm demonstrado que as épocas de plantio não afetam o número potencial de grãos, e que a disponibilidade de assimilados para a espiga no período de pegamento dos grãos, a taxa de crescimento da cultura ao redor do florescimento, o abortamento de grãos e as densidades de plantas são os fatores determinantes do número final de grãos (Prior \& Russell, 1975; Tollenaar, 1977; Andrade et al., 1992, 1993a, 1993b; Tollenaar et al., 1992; Cirilo \& Andrade, 1994b; Otegui \& Melón, 1997). Assim, quando o número final de grãos é menor do que o número potencial, os grãos restantes adquirem maior capacidade de mobilizar assimilados, tornando-se mais pesados.

Quando a fonte parece ser o fator limitante, como neste estudo, principalmente em épocas de plantio mais tardias (Figura 7), o aumento da oferta de fotoassimilados poderia ser obtido pela redução da população de plantas, como proposto por Jones \& Simmons (1983). Nas situações em que a capacidade dos grãos em alocar fotoassimilados é o fator limitante, como em plantios mais precoces na Região Sul do Brasil, pode-se aumentar a densidade de plantas, para que haja um aumento na interceptação e conversão da radiação, de modo a promover um equilíbrio na relação fonte/dreno, sem que a taxa e a duração do período de enchimento de grãos sejam substancialmente alteradas (Daynard et al., 1971; Schoper et al., 1982; Magalhães \& Jones, 1990a; Stewart et al., 1997). O aumento da densidade de plantas, nesse caso, seria acompanhado por um aumento do número de grãos por unidade de área, e não pelo aumento no número de grãos por planta, que parece ser predeterminado, refletindo o potencial genético da planta (Magalhães \& Jones, 1990b; Uhart \& Andrade, 1995). Apesar de tolerar altas densidades de plantas, os híbridos modernos são mais sensíveis a condições de estresse em anos com baixa precipitação pluvial, provocando diminuição na ca- pacidade dos drenos em acumular os fotoassimilados disponíveis (Ouattar et al., 1987; Cox, 1996). Além do estresse hídrico, a diminuição da disponibilidade de radiação incidente próximo ao florescimento, como conseqüência direta da alta densidade populacional, pode limitar a taxa de crescimento da espiga, além de abortamento das flores já desenvolvidas, e diminuir principalmente o número de grãos por espiga (Otegui, 1997).

\section{Conclusões}

1. A taxa efetiva de crescimento de grãos nos plantios precoces é maior do que nos plantios tardios, o que resulta em grãos mais pesados.

2. A menor temperatura média do ar no período efetivo de crescimento dos grãos em plantios tardios reduz a taxa e o tempo efetivo do crescimento dos grãos, e resulta em grãos mais leves.

3. Nas condições do Rio Grande do Sul, em plantios de híbridos de milho efetuados mais tardiamente, os principais fatores limitantes do rendimento estão relacionados com a fonte produtora de fotoassimilados, enquanto em plantios mais precoces o principal fator limitante do rendimento é o baixo número de grãos por unidade de área.

\section{Referências}

ALUKO, G. K.; FISCHER, K. S. The effect of changes of assimilate supply around flowering on grain sink size and yield of maize (Zea mays L.) cultivars of tropical and temperate adaptation. Australian Journal of Agricultural Research, Collingwood, v. 39, p. 153-161, 1988.

ANDRADE, F. H.; UHART, S. A.; ARGUISAIN, G. G.; RUIZ, R. A. Radiation use efficiency of maize grown in a cool area. Field Crops Research, Amsterdam, v. 28, p. $345-354,1992$.

ANDRADE, F. H.; UHART, S. A.; CIRILO, A. Temperature affects radiation use efficiency in maize. Field Crops Research, Amsterdam, v. 32, p. 17-25, 1993a.

ANDRADE, F. H.; UHART, S. A.; FRUGONE, M. I. Intercepted radiation at flowering and kernel number in maize: shade versus plant density effects. Crop Science, Madison, v. 33. p. 482-485, 1993b. 
CIRILO,A. G.; ANDRADE, F. H. Sowing date and kernel weight in maize. Crop Science, Madison, v. 36, p. 325-331, 1996.

CIRILO, A. G.; ANDRADE, F. H. Sowing date and maize productivity. I. Crop growth and dry matter partitioning. Crop Science, Madison, v. 34, p. 1039-1043, 1994a.

CIRILO, A. G; ANDRADE, F. H. Sowing date and maize productivity. II. Kernel number determination. Crop Science, Madison, v. 34, p. 1044-1046, 1994b.

COX, W. J. Whole-plant physiological and yield responses of maize to plant density. Agronomy Journal, Madison, v. 88 , p. $489-496,1996$

DAYNARD, T. B.; TANNER, J. W.; DUNCAN, W. G. Duration of grain filling period and its relation to grain yield in corn, Zea mays L. Crop Science, Madison, v. 11, p. 45-48, 1971.

GIAUFFRET, C.; BONHOMME, R.; DORVILLEZ, D.; DERIEUX, M. Conversion of intercepted radiation into aerial dry biomass for three maize genotypes: influence of plant density. Maydica, Bergamo, v. 36, p. 25-27, 1991.

GRANT, R.F. Simulation of carbon assimilation and partitioning in maize. Agronomy Journal, Madison, v. 81, p. $563-571,1989$

JACOBS, B. C.; PEARSON, C. J. Potential yield of maize determined by rates of growth and development of ears Field Crops Research, Amsterdam, v. 27, p. 281-298, 1991

JOHNSON, D. R.; TANNER, J. W. Calculation of the rate and duration of grain filling in corn (Zea mays L.). Crop Science, Madison, v. 12, p. 485-489, 1972.

JONES, R. J.; ROESSLER, J.; OUATTAR, S. Thermal environment during endosperm cell division in maize effects on number of endosperm cells and starch granules Crop Science, Madison, v. 25, p. 830-834, 1985.

JONES, R. J.; SCHREIBER, B. M. N.; ROESSLER, J. A Kernel sink capacity in maize: genotypic and maternal regulation. Crop Science, Madison, v. 36, p. 301-306, 1996

JONES, R. J.; SIMMONS, S. R. Effect of altered source sink relation on growth of maize kernels. Crop Science, Madison, v. 23, p. 129-134, 1983.

MADDONNI, G. A.; OTEGUI, M. E.; BONHOMME, R Grain yield components in maize. II. Postsilking growth and kernel weight. Field Crops Research, Amsterdam, v. 56, p. $257-264,1998$
MAgAlhães, P. C.; JONES, R. Aumento de fotoassimilados na taxa de crescimento e peso final dos grãos de milho. Pesquisa Agropecuária Brasileira, Brasília, v. 25, n. 12, p. 1747-1754, dez. 1990a.

MAGAlHÃES, P. C.; JONES, R. Aumento de fotoassimilados sobre teores de carboidratos e nitrogênio em milho. Pesquisa Agropecuária Brasileira, Brasília, v. 25 , n. 12 , p. $1755-1761$, dez. 1990 b.

MUCHOW, R. C. Effect of high temperature on graingrowth in field-grown maize. Field Crops Research, Amsterdam, v. 23, p. 145-158, 1990.

OTEGUI, M. E. Kernel set and flower synchrony within the ear of maize. II. Plant population effects. Crop Science, Madison, v. 37, p. 448-455, 1997.

OTEGUI, M. E.; MELÓN, S. Kernel set and flower synchrony within the ear of maize. I. Sowing date effects. Crop Science, Madison, v. 37, p. 441-447, 1997.

OTEGUI, M. E.; NICOLINI, M. G.; RUIZ, R. A.; DODDS, P. A. Sowing date effects on grain yield components for different maize genotypes. Agronomy Journal, Madison, v. 87, p. 29-33, 1995.

OUATTAR, S.; JONES, R. J.; CROOKSTON, R. K. Effect of water deficit during grain filling on the pattern of maize kernel growth and development. Crop Science, Madison, v. 27, p. $726-730,1987$

PRIOR, C. L.; RUSSELL, W. A. Yield performance of non-prolific and prolific maize hybrids at six plant densities. Crop Science, Madison, v. 15, p. 482-486, 1975

SCHOPER, J. B.; JOHNSON, R. R.; LAMBERT, R. J. Maize yield response to increased assimilate supply. Crop Science, Madison, v. 22, p. 1184-1189, 1982.

SETTER, T. L.; FLANNIGAN, B. A. Sugar and starch redistribution in maize in response to shade and ear temperature treatment. Crop Science, Madison, v. 26, p. $575-579,1986$.

STEWART, D. W.; DWYER, L. M.; ANDREWS, C. J.; DUGAS, J. A. Modeling carbohydrate production, storage, and export in leafy and normal maize (Zea mays L.). Crop Science, Madison, v. 37, p. 1228-1236, 1997.

TOLLENAAR, M. Is low plant density a stress in maize? Maydica, Bergamo, v. 37, p. 305-311, 1992.

TOLLENAAR, M. Response of dry matter accumulation in maize to temperature. I. Dry matter partitioning. Crop Science, Madison, v. 29, p. 1239-1246, 1989.

TOLLENAAR, M. Sink-source relationships during reproductive development in maize: a review. Maydica, Bergamo, v. 22, p. 49-75, 1977

Pesq. agropec. bras., Brasília, v. 36, n. 3, p. 447-456, mar. 2001 
TOLLENAAR, M.; DAYNARD, T. B. Relationship between assimilate source and reproductive sink in maize grown in a short-season environment. Agronomy Journal, Madison, v. 70, p. 219-223, 1978

TOLLENAAR, M.; DWYER, L. M.; STEWART, D. W. Ear and kernel formation in maize hybrids representing three decades of grain yield improvement in Ontario. Crop Science, Madison, v. 32, p. 432-438, 1992.
TOlLENAAR, M.; McCullough, D. E.; DWYER, L. M. Physiological basis of the genetic improvement of corn. In: SLAFER, G. A. (Ed.). Genetic improvement of field crops. New York : M. Dekker, 1994. p. $183-236$

UHART, S. A.; ANDRADE, F. H. Nitrogen deficiency in maize. I. Effects on crops growth, development, dry matter partitioning, and kernel set. Crop Science, Madison, v. 35, p. 1376-1383, 1995. 